\title{
A saúde na proposta de desenvolvimento da Comissão Econômica para a América Latina e o Caribe (CEPAL)/ Organização Pan-Americana da Saúde (OPAS)
}

Health in the development proposal of the Economic Commission for Latin America and the Caribbean (ECLAC) / Pan American Health Organization (PAHO)

Maria Lucia Frizon Rizzotto'

Doutora em Saúde Coletiva pela Universidade Estadual de Campinas

(UNICAMP) - Campinas (SP), Brasil. Professora

da Universidade Estadual do Oeste do Paraná

(UNIOESTE) - Cascavel (PR), Brasil.

frizon@terra.com.br
RESUMO Este trabalho de natureza documental buscou identificar as razões para a incorporação da saúde no projeto de desenvolvimento para os países da América Latina elaborado pela Comissão Econômica para a América Latina e o Caribe (CEPAL) no início da década de 1990, e o papel atribuído ao setor saúde na proposta construída em conjunto com a Organização Pan-Americana de Saúde (OPAS), intitulada Salud, equidad y transformación productiva en América Latina y el Caribe. Foram utilizados como fontes documentos elaborados pela CEPAL e publicações conjuntas com com a OPAS. Dentre os resultados, destacam-se a visão da saúde como fator de desenvolvimento econômico e social, e a noção de enfoque integrado como principal argumento para a incorporação da saúde no novo marco de desenvolvimento regional, além da centralidade das categorias de equidade e produtividade nas referidas propostas.

PALAVRAS CHAVE: CEPAL; OPAS; Desenvolvimento e Saúde; Equidade.

\begin{abstract}
This work of documentary nature sought to identify the reasons for the incorporation of health in the development project for the Latin American countries prepared by the Economic Commission for Latin America and the Caribbean (ECLAC) in the early 1990s, and the role assigned to the health sector in the built proposition in conjunction with the Pan American Health Organization (PAHO), entitled Salud, equidad y transformación productiva en América Latina y el Caribe. It was used as source documents prepared by ECLAC and in combination with PAHO. Among the results, we highlight the view of health as a factor of economic and social development, besides the notion of integrated approach as the main argument for the incorporation of health in the new framework of regional development, and the centrality of the categories of equity and productivity in these referred proposals.
\end{abstract}

KEYWORDS: ECLAC; PAHO; Development and Health; Equity. 


\section{Introdução}

A Comissão Econômica para a América Latina e o Caribe (CEPAL) foi criada em 1948 pelo Conselho Econômico e Social das Naçóes Unidas para coordenar e acompanhar as políticas direcionadas à promoção do desenvolvimento econômico dos países latino-americanos e reforçar as relaçóes econômicas desses países entre si e com as demais naçóes do mundo. Em 1996, os governos dos Estados-membros definiram como tarefa central da CEPAL a

\section{[...] formulação, seguimento e avaliação de políticas públicas e a prestação de serviços operativos nos campos da informação especia- lizada, assessoramento, capacitação e apoio à cooperação e coordenação regional e internacio- nal. (COMISIÓN ECONÓMICA PARA AMÉRICA LATINA Y EL CARIBE, 2006, p. 1).}

No início dos anos 1990, em resposta aos péssimos resultados econômicos e sociais das políticas de ajuste colocadas em prática pelos países da região nos anos 1980 - considerados como uma década perdida $^{1}$, a CEPAL apresentou uma nova proposta de desenvolvimento para a América Latina e o Caribe, sintetizada na publicação denominada Transformación Productiva con Equidad: la tarea prioritaria del desarrollo de América Latina y el Caribe en los años noventa (COMISIÓN ECONÓMICA PARA AMÉRICA LATINA Y EL CARIBE, 1990). Este texto orientou, nas décadas seguintes, a elaboração de documentos e políticas específicas para diferentes áreas sociais, entre elas, a saúde. Para esta área, o documento base foi produzido em conjunto com a Organização Pan-Americana de Saúde (OPAS) e denomina-se Salud, equidad y transformación productiva en América Latina y el Caribe ${ }^{2}$ (ORGANIZAÇÃO
PAN-AMERICANA DA SAÚDE; COMISIÓN ECONÓMICA PARA AMÉRICA LATINA Y EL CARIBE, 1997).

Embora a CEPAL não seja a única instituição que produz análises e propostas para os setores econômicos e, mais recentemente, para os diferentes setores sociais, reconhecidamente é uma importante instituição regional que dá sustentação com referenciais teórico-práticos para os governos dos diferentes países da regiáo. A relevância de se estudar as proposiçóes da CEPAL para o setor saúde deve-se ao fato de essa instituição ter o peso que tem na orientação da área econômica dos governos dos países latino-americanos, bem como ao entendimento que temos da relação de subordinação que os setores sociais historicamente têm em relação às políticas econômicas.

Assim, o presente estudo documental teve como objetivo identificar as possíveis razóes para a incorporação da saúde no projeto de desenvolvimento da CEPAL e o papel atribuído a este setor na proposta elaborada em conjunto com a OPAS no início da década de 1990. Buscou-se, ainda, compreender a aproximação da CEPAL (instituição que tradicionalmente se ocupa de aspectos econômicos) com a OPAS (que trata de questóes relacionadas com a saúde), fato que apenas tangencialmente havia ocorrido na década de 1960, no auge da planificação do desenvolvimento na região. Assim, identificar os enfoques teóricos e os campos de análise que fundamentaram o diagnóstico e a nova proposta poderia contribuir para ajudar a explicar essa aproximação. Em nosso entendimento, a noção de enfoque integrado, a centralidade da categoria equidade $^{3}$ e a retomada do planejamento no período posterior à ofensiva neoliberal do Consenso de Washington se constituíram em fatores determinantes desse processo, sem que a CEPAL abandonasse as linhas centrais da sua visão de desenvolvimento.

1 O entendimento da década de 1980 como a década perdida baseava-se na análise de que, neste período, houve perda de dinamismo, desequilíbrio macroeconômico, ajuste de caráter regressivo, debilitamento do setor público e decréscimo de investimentos, que retrocederam aos níveis do início da década de 1970, provocando retrocesso econômico e social na maioria dos países da região latino-americana.

2 Este documento foi aprovado no XXV Período de Sessões da CEPAL, em abril de 1994, e pela XXIV Conferência Sanitária Pan-Americana da OPAS, realizada em setembro de 1994, além das propostas terem sido apoiadas e incluídas no Plano de Ação da Cúpula das Américas, realizada em Miami, neste mesmo ano.

${ }^{3}$ Uma análise crítica sobre a categoria 'equidade' pode ser vista no artigo de RIZZOTTO, M. L. F; BORTOLOTO, C. O conceito de equidade no desenho de políticas sociais: pressupostos políticos e ideológicos da proposta de desenvolvimento da CEPAL. Interface, Botucatu, SP, v. 15, n. 38, p. 793-804, 2011. 


\section{Saúde e desenvolvimento: o enfoque integrado}

Na proposta de desenvolvimento da CEPAL, denominada Transformação Produtiva com Equidade (TPE), adotou-se a noção de enfoque integrado como perspectiva de análise a partir da avaliaçáo de que não tinham sido frutíferas as abordagens que tratavam as políticas econômicas e as políticas sociais como dois mundos separados. Essa visão fragmentada teria levado a contraposiçóes que não beneficiaram nem o crescimento nem a equidade, uma vez que as políticas não são neutras em termos distributivos e ambas poderiam influenciar o desenvolvimento econômico. Portanto, teria chegado o momento de superar a ideia de que a única finalidade da política econômica seria conseguir um crescimento adequado na esfera da produção, e à política social caberia a tarefa de se ocupar de problemas relacionados com a distribuição. Assim, o uso do enfoque integrado permitiria o apoio recíproco e a complementação entre as medidas de fomento da competitividade e aquelas capazes de promover a coesão social, objetivos centrais da proposta de TPE. No entendimento da CEPAL, por meio do enfoque integrado seria possível [...] privilegiar aquellas politicas económicas que también favorezcan la equidad, y las politicas sociales que consideren la productividad y la eficiência (ORGANIZAÇÃO PAN-AMERICANA DA SAÚDE; COMISIÓN ECONÓMICA PARA AMÉRICA LATINA Y EL CARIBE, 1997, p. 4).

$\mathrm{O}$ novo enfoque seria útil para o crescimento e o desenvolvimento econômico, uma vez que este resultaria tanto da política econômica como da política social. Da mesma forma, a equidade social sofreria a influência da política social e dos efeitos da política econômica. Assim, era necessário [...] un enfoque integrado que permita que la politica pública en su conjunto apoye, a la vez, la transformación productiva ambientalmente sostenible y la equidad (ORGANIZAÇÃO PAN-AMERICANA DA SAÚDE; COMISIÓN ECONÓMICA PARA AMÉRICA LATINA Y EL CARIBE, 1997, p. 5).

Esse argumento seria particularmente relevante para a área da saúde, em face de que este setor desempenha uma dupla função: tanto é 'um bem final', ou seja, o seu consumo satisfaz necessidades, como é um 'bem de capital', que contribui para a produção de outros bens finais.

A importância do enfoque integrado para a consecução da proposta de TPE mereceu aprofundamentos da própria CEPAL, por meio de outros documentos publicados posteriormente como Equidad y Transformación Productiva: un enfoque integrado (COMISIÓN ECONÓMICA PARA AMÉRICA LATINA Y EL CARIBE, 2008, p. 1), onde destaca-se que [...] existen zonas significativas y todavia no bien exploradas donde equidad y transformación productiva se complementan $y$ se refuerzan mutuamente. Para esta instituição, existiria uma complementaridade, ainda pouco explorada, entre as açóes que visam ao crescimento econômico e aquelas que buscam maior equidade social em um horizonte de melhor produtividade do trabalho.

Além disso, outro aspecto precisaria ser levado em conta: a necessidade de conciliar crecimiento, equidad y democracia, pois

\section{[...] asi como la equidad no puede alcanzarse} en ausencia de un crecimiento sólido y sostenido, el crecimiento exige un grado razonable de estabilidad sociopolitica, y ésta implica, a su vez, cumplir con ciertos requisitos minimos de equidad. (COMISIÓN ECONÓMICA PARA AMÉRICA LATINA Y EL CARIBE, 2008, p. 2).

Assim, a tarefa histórica daquele momento seria alcançar ambos os objetivos, aproximar a democracia dos princípios liberais de governabilidade e governança.

Dessa forma, a CEPAL entendia que estava se diferenciando de muitos governos latino-americanos que colocaram ênfase nas políticas sociais e de organismos internacionais que formularam propostas visando a amenizar a pobreza, promovendo apenas o crescimento econômico. O enfoque integrado teria como desafio propor políticas que aproveitassem e reforçassem as complementaridades e debilitassem as oposiçóes, reduzindo o eterno conflito entre crescimento e equidade, onde um avança à custa do outro.

No entendimento da CEPAL (2008, p. 4-5), entre os três grandes conjuntos de políticas que levam à equidade, ou seja, o aumento do emprego produtivo, 
o investimento em capital humano e as transferências de renda, somente o último se daria às expensas do crescimento. $\mathrm{O}$ investimento em capital humano, que envolve o investimento em saúde, embora de imediato possa significar [...] el sacrificio de un nivel modesto de crecimiento en el presente en aras de un mayor crecimiento en el futuro, pero a la larga esa inversión beneficia la competitividad y la equidad., uma vez que saúde deficiente levaria à subutilização do potencial capital humano do trabalhador, logo [...] cuanto más saludable sea la fuerza de trabajo, mayor será también la productividad total de los factores en la productividad de bienes $y$ servicios.

A reatualização da Teoria do Capital Humano, criada por Theodore W. Schultz na década de 1950, no coração do neodesenvolvimentismo, buscava explicar os ganhos de produtividade gerados pelo 'fator humano’ na produção. Essa teoria ganha força na década de 1960, no interior de teorias que buscavam explicar o desenvolvimento/subdesenvolvimento. $\mathrm{O}$ investimento em educaçấo e o acúmulo de habilidades emergem como fatores para a superaçáo da pobreza e a promoção do desenvolvimento econômico (SCHULTZ, 1973). Na década de 1990 , a CEPAL recoloca essa teoria no centro de sua proposta de TPE.

\section{A Transformação Produtiva com Equidade (TPE)}

O documento que fundamentou as proposiçóes da CEPAL a partir da década de 1990 - Transformación Productiva con Equidad: la tarea prioritaria del desarrollo de América Latina y el Caribe en los años noventa - parte da análise dos ensinamentos apreendidos com as crises econômicas da década de 1980 e apresenta uma proposta de desenvolvimento para os governos dos Estados-membros, sintetizada no desafio comum a todos os países da região de transformarem ou atualizarem as estruturas produtivas no marco das condiçôes econômicas (lógicas de acumulação e a nova divisão internacional do trabalho), tecnológicas (sociedade do conhecimento - o capital humano) e sociais (estabilidade e coesão) da economia global.
A CEPAL parte do princípio que a regiáo tem condiçôes de superar o seu atraso em relação às outras partes do mundo se fizer melhor uso dos recursos e vantagens que possui. Sua proposta de TPE se fundamenta em uma concepção atualizada de desenvolvimento - o sustentável -, cujos objetivos básicos seriam: crescer, melhorar a distribuição de renda, consolidar a democracia, adquirir maior autonomia, combater a deteriorização ambiental e melhorar a qualidade de vida de toda a população. A proposta apresenta açóes para enfrentar as consequências da inércia recessiva dos anos 1980, a dívida externa e a inadequação entre as estruturas da demanda internacional, e a composição das exportações da região (COMISIÓN ECONÓMICA PARA AMÉRICA LATINA Y EL CARIBE, 1990).

Embora faça críticas à década de 1980, a instituiçáo analisa que nem tudo teria sido perdido, era possível tirar liçóes para a área econômica e avanços no campo político. $\mathrm{Na}$ área econômica, ficara evidente a necessidade de melhorar a inserção da região na dinâmica mundial, aumentando sua competitividade internacional, mantendo o equilíbrio macroeconômico e complementando com políticas setoriais (mediante reformas institucionais de segunda geração) que dessem apoio às transformações. No campo político, a década teria como principal ganho a progressiva desideologização do debate político e econômico, e o aumento da cooperação intrarregional, superando a debilidade das instituições públicas e a conflitividade social.

O diagnóstico indicava a necessidade de uma inflexão no padrão de desenvolvimento vigente, colocando para os governos o desafio de realizar uma série de tarefas que recolocasse a região no caminho do desenvolvimento, sendo elas: o fortalecimento da democracia; o ajuste das economias; a estabilização e a incorporação das mudanças tecnológicas; a modernização dos setores públicos; o aumento dos investimentos na economia; a melhoria na distribuição de renda; e a implementação de padróes de consumo mais austeros, em um contexto de desenvolvimento sustentável.

O documento apresenta também uma análise sobre os determinantes internos e externos que deveriam ser levados em conta na operacionalização da TPE. Sobre o entorno externo, os elementos centrais referem-se 
ao grau de abertura do comércio internacional, ao manejo do endividamento externo e ao acesso a novos conhecimentos e tecnologias. Sob o ponto de vista interno, permaneceria o desafio de corrigir os desequilíbrios macroeconômicos e investir no desenvolvimento econômico, apesar da permanência de transferências de recursos para o exterior em face do pagamento da dívida, ademais da necessidade de manter a coesão social, apesar de as açóes para a manutenção dessa coesão imporem limites às políticas e estratégias econômicas. Também analisa que, se os governos latino-americanos adotassem estratégias regionais, como por exemplo, a organização em blocos com alianças em vez de acordos bilaterais, teriam mais legitimidade, credibilidade e eficácia nas negociações no comércio internacional de matérias e bens manufaturados, além de isso ser mais adequado para o enfrentamento dos problemas relacionados ao meio ambiente e aos recursos naturais (COMISIÓN ECONÓMICA PARA AMÉRICA LATINA Y EL CARIBE, 1990).

A partir desse diagnóstico inicial, o documento apresenta com detalhes os critérios, as orientaçóes e o contexto institucional que daria sustentação à proposta de TPE. Em relação aos 'critérios', avalia que a TPE deveria ocorrer em um contexto de maior competitividade internacional, sustentada mais pelo aumento da produtividade e pela incorporação deliberada do progresso técnico nos processos produtivos (competiçãao autêntica) do que pela depreciação dos salários (competição espúria). Analisa que a região, até então, teria utilizado de forma insuficiente os conhecimentos técnicos disponíveis em nível internacional, e que a industrialização, por incorporar e difundir o progresso técnico mais rapidamente do que outros setores, deveria se constituir no eixo da transformação produtiva, ultrapassando o marco tradicional da industrialização de setores da economia, se integrando com as exportaçóes de produtos primários e com o setor de serviços, sem esquecer-se da preservação do meio ambiente.

Quanto às 'orientações' para o desenho de políticas, visando à TPE, estas deveriam combinar o manejo macroeconômico com políticas setoriais. Para isto, seria preciso promover mudanças institucionais que favorecessem a articulação entre o setor público e o setor privado, objetivando a equidade e a harmonia social, a partir de uma perspectiva mais retributiva do que distributiva de bem-estar, ou seja, deveria instituir-se uma nova relação entre Estado e sociedade civil - entendendo esta como uma rede de organização de proprietários, grupos comunitários, agências de cooperação, ONGs, associaçóes civis, e no conceito de responsabilidade social empresarial e de empreendimento.

As políticas fiscal e setorial deveriam assumir um caráter redistributivo para alcançar a equidade desejada. Para isto, seria necessário associar ajuda técnica, financeira e de comercialização com programas massivos de capacitação para microempresários, trabalhadores autônomos e camponeses, além de reduzir os entraves burocráticos e institucionais que estariam impedindo a formação de microempresas. Por fim, os países deveriam realizar reformas nos serviços sociais visando aos setores mais pobres, mediante políticas compensatórias de afirmação positiva, e criando mecanismos que permitissem a apresentação de demandas ao Estado, ou seja, ampliando os espaços de participaçáo - cooperativa - nos marcos da democracia liberal.

Em relação à intervenção estatal, o documento ressalta que, na década de 1980, os Estados privilegiaram a expansão da economia visando ao pagamento dos serviços da dívida externa. Agora, eles deveriam priorizar o fortalecimento da competitividade com base na incorporação do progresso técnico e no aumento da equidade. Para isto, não precisariam, necessariamente, aumentar ou diminuir a ação pública, mas apenas contribuir para a eficácia do sistema econômico em seu conjunto, por meio do exercício de uma coordenação intersetorial, do suporte técnico para gerar uma competitividade autêntica e de novas técnicas de planejamento. Assim, a intervenção pública teria como tarefa central o estabelecimento de um conjunto de acordos de longo prazo entre um Estado Management e os atores políticos e sociais da sociedade civil corporativizada. Tais acordos funcionariam por meio de mecanismos de concertación, que dariam legitimidade às açóes e possibilitariam o desenvolvimento de comportamentos convergentes com as propostas comuns, inibindo a 'guerra' de interesses particularistas que poderia colocar em risco a TPE. Ressalta, ainda, que a concertação 
nunca é definitiva, mas posta à prova cotidianamente, o que exigiria uma grande capacidade governamental para firmar acordos. A região precisaria desta ação para legitimar sistemas políticos sustentados nas noçóes de pluralismo e de participação, advindos da democracia consensualista do liberalismo político.

Apesar das especificidades de cada país, no documento, analisa-se que há uma convergência sobre a necessidade de transformar as estruturas produtivas e o papel do progresso técnico para o crescimento sustentável mais equitativo. O que varia de um país para o outro é a forma de utilizar os instrumentos, o desenho institucional e a prioridade dada às mudanças políticas. Isto estaria relacionado com a estrutura produtiva, o tamanho da economia, o processo de industrialização existente em cada país, além de com o aparato do Estado. A recomendação é de que o crescimento com equidade deve orientar a oferta e o uso de serviços sociais para o maior desenvolvimento produtivo das pessoas a fim de capacitá-las para uma inserção mais dinâmica no sistema econômico.

Elementos constitutivos dessa proposta, em maior ou menor intensidade e com alguma diferença temporal, foram assimilados pela quase totalidade dos governos latino-americanos a partir da década de 1990, compondo políticas econômicas e sociais. Contribuiu para isto a objetividade da proposta, sua aparente neutralidade e a inclusão da noção de equidade, vinculada ideologicamente a uma teoria liberal de justiça, que tem como centro reflexivo princípios reguladores de uma 'sociedade bem ordenada' e minimamente 'justa', onde o Estado assume certo protagonismo na correção das desigualdades sociais. Esta teoria tem em John Rawls (1997; 2003) seu principal pensador.

\section{Saúde, equidade e transformação produtiva na América Latina e no Caribe}

Considerando a importância da categoria equidade e seu oposto - iniquidade - nos documentos da OPAS/ CEPAL e seu uso indiscriminado no desenho, na justificativa e na avaliação de políticas sociais, geralmente como sinônimo de igualdade/desigualdade, cabe aqui precisar posiçóes distintas acerca de seu significado. Para a CEPAL (2006, p. 63) equidade é [...] la relación entre el ingreso del $40 \%$ de la población de ingresos más bajos y el 10\% de la de ingresos más altos, tratase de uma comparação entre os estratos sociais extremos que compóe uma dada sociedade em termos de apropriação de renda, podendo ser entendida também como desigualdade ou diferenças sociais.

No documento elaborado pela OPAS/CEPAL (1997, p. 45), equidade em saúde é entendida como a

[...] redución de las disparidades en las condiciones de salud de los diferentes grupos sociales y garantía al acceso de toda población a la atención de sus necesidades básicas de salud.

Breilh (2010, p. 104), por sua vez, recuperando o debate sobre equidade e classe social, diferencia equidade/iniquidade de igualdade/desigualdade afirmando que:

[...] la inequidad es la categoría que define las relaciones y contrastes de poder que existen en una formación social; es el resultado de una historia de acumulación de poder y resulta de un proceso en que una determinada clase social se apropia de las condiciones del poder que son generalmente interdependientes: apropiación y acumulación económica, politica y cultural.

E define desigualdade como

[...] una expresión resultante de esa inequidad y expresa una injusticia en el reparto o acceso de los bienes y servicios que existen en una sociedad. Es decir mientras la inequidad es una categoría explicativa, la desigualdad es una expresión observable de la inequidad. (BREIH, 2010, p. 105).

Neste trabalho, por se tratar de uma análise de documentos institucionais, o sentido é aquele atribuído pela instituição objeto de estudo. 
O documento intitulado Salud, equidad y transformación productiva en América Latina y Caribe, como dissemos, é uma elaboração conjunta da CEPAL e da OPAS e, assumidamente, se constitui na política oficial dos dois organismos para a área da saúde. As bases para a sua construção foram a proposta de Transformaçáo Produtiva com Equidade da CEPAL, de 1990, e as Orientaçóes Estratégicas e Prioridades Programáticas da OPAS para o triênio 1991-1994, denominada Saúde e Desenvolvimento Humano (ORGANIZAÇÃO PAN-AMERICANA DA SAÚDE; COMISIÓN ECONÓMICA PARA AMÉRICA LATINA Y EL CARIBE, 1997).

Segundo o documento conjunto, para a análise da situação da saúde e a elaboração das propostas para este setor foi adotado o 'enfoque integrado ou multissetorial', que pretendeu dar fim ao entendimento de que as políticas de saúde são de responsabilidade apenas do setor saúde. Desta forma, buscou-se identificar as relaçóes existentes entre saúde e desenvolvimento, elaborando uma proposta com três linhas centrais: 1) Adoção de políticas intersetoriais de promoção e prevenção; 2) Reformas do setor saúde visando a superar as iniquidades de acesso, utilização de serviços e atendimento das demandas decorrentes da transição epidemiológica; e 3) Aumentar a eficiência no modo de operar e financiar o setor (ORGANIZAÇÃO PAN-AMERICANA DA SAÚDE; COMISIÓN ECONÓMICA PARA AMÉRICA LATINA Y EL CARIBE, 1997).

Embora essa não tenha sido a primeira atividade conjunta das duas instituiçóes ${ }^{4}$, a proposta atual 'incorpora a saúde no núcleo da transformação produtiva com equidade', que se constituiria em uma nova visão sobre o desenvolvimento na América Latina e no Caribe (OPAS/CEPAL, 1997, p. vii). Esta nova visão se baseia no entendimento de que há um 'círculo virtuoso' entre saúde e desenvolvimento econômico, uma vez que é fundamental aumentar a produtividade e a equidade para que os países da região, melhorando as suas condiçóes de desenvolvimento, possam competir no mercado internacional. Neste sentido, a saúde teria muito a contribuir para aumentar a produtividade do trabalhador. Com base no enfoque integrado, os setores sociais, em geral, e a saúde, em particular, passariam a adquirir importância, sobretudo como [...] factor de formación, mantenimiento y perfeccionamiento del capital humano (ORGANIZAÇÃO PAN-AMERICANA DA SAÚDE; COMISIÓN ECONÓMICA PARA AMÉRICA LATINA Y EL CARIBE, 1997, p. 1). Trata-se de uma visão produtivista da força de trabalho, além de este setor ser importante dinamizador da economia, tanto como empregador como produtor de bens e serviços.

$\mathrm{Na}$ medida em que os objetivos econômicos e sociais do desenvolvimento estão articulados entre si, conforme indica o enfoque integrado, os setores sociais também deveriam se constituir em parte integrante das políticas de desenvolvimento. No caso da saúde, são elencadas cinco razóes para se investir neste setor, no marco da TPE: Primeira razão - a elevação do nível de saúde da populaçáo influencia positivamente a produtividade e o desenvolvimento integral dos recursos humanos.

La reducción de la morbilidad general, y de la
morbilidad y desnutrición infantiles en par-
ticular, permite una disminución de los días
perdidos de trabajo y capacitación, un mejor
desempeño laboral y un notorio incremento del
rendimiento escolar.

Segunda razão - o setor saúde se caracteriza pelo uso intensivo de mão de obra [...] en tareas como formación y adestramiento del persona, producción y suministro de insumos, mantenimiento de instalaciones y de equipos, $y$ otras. Terceira razáo - o setor saúde tem um alto potencial de crescimento e é um setor de dinamizaçáo da economia:

[...] a medida que los paises crecen aumenta la participación del sector salud en el PIB. El costo de la atención de la salud aumenta debido a la mayor frecuencia de enfermedades degenerativas $y$ al desarrollo de tecnologías sanitarias de alto costo.

${ }^{4}$ Por ocasião da Conferência de Punta del Este, em 1961, ambas atuaram colaborativamente para incluir a saúde na planificação do desenvolvimento regional. 
Quarta razão - o cumprimento das exigências derivadas das normas sanitárias favorece a competitividade internacional e permite combinar progressivamente a competitividade com qualidade dos produtos e serviços do setor saúde. Quinta razão - a saúde é um âmbito especialmente adequado para melhorar a equidade:

La extensión del acceso a los servicios de salud puede influir en la distribución del ingreso y elevar el nivel de vida de los pobres a un costo inferior al que suponen las politicas de vivienda y en un plazo más breve que la educación. (OPAS/CEPAL, 1997, p. 8).

Note-se que, em todas as razóes elencadas, o argumento é no sentido de evidenciar a vinculação entre saúde e desenvolvimento com destaque para o 'fator humano', além de a saúde ser considerada uma área importante para expansão e valorização do capital. Atualmente, cerca de $12 \%$ do PIB mundial são gastos no setor saúde. Certamente, nos países desenvolvidos este volume é bem maior do que a média dos países da região, de 5,7\%. Mesmo assim, estes são valores nada desprezíveis para investimentos do capital. No Brasil, em 2009, quase $9 \%$ do PIB foram gastos com o consumo de bens e serviços de saúde (SCHINCARIOL, 2012).

A qualidade do 'capital humano' disponível é central na proposta da CEPAL para elevação da produtividade, tanto para melhorar a competitividade internacional como para alcançar uma maior equidade. Neste sentido, de acordo com a OPAS/CEPAL (1997), o setor saúde teria particular importância na medida em que problemas de saúde aumentam a quantidade de dias parados; reduzem o rendimento do trabalhador; produzem desânimo e má disposição para cooperar; prejudicam a atenção no desempenho do trabalho, o que repercute na qualidade dos produtos; e reduzem a curiosidade, a iniciativa e a capacidade de aprender. $\mathrm{Ou}$ seja, a saúde deficiente implicaria em uma subutilização do potencial capital humano.

Conclui-se, então, que o investimento em saúde [...] sirve, como toda inversión en recursos humanos, tanto para el crecimiento como para la equidad. Isso além de os resultados dos investimentos em saúde se manifestarem de forma mais imediata do que os frutos de outros gastos com recursos humanos, como, por exemplo, na educação e na capacitação (ORGANIZAÇÃO PANAMERICANA DA SAUUDE; COMISIÓN ECONÓMICA PARA AMÉRICA LATINA Y EL CARIBE, 1997, p. 5).

Contudo, para se investir em saúde seria necessário considerar a 'rentabilidade' desses investimentos, ou seja, a relação custo atual/benefícios futuros para o incremento da produtividade. $\mathrm{O}$ documento elenca três razóes que indicariam ser possível haver menos gastos em saúde por unidade de produto nos países em desenvolvimento do que nos países centrais, sendo elas: 1) O custo da mão de obra aqui é menor do que nos países centrais, a região [...] forma capital humano para salud a un costo muy inferior al de los países desarrollados; 2) Parte dos gastos em saúde [...] son bienes de un costo excepcionalmente bajo y de un alto impacto en la salud pública; e 3) A esperança de vida das pessoas em idade para se aposentar [...] es muy superior en los paises desarrollados que en los latinoamericanos y caribeños. Porém, para manter estas 'vantagens', seria necessário um cuidado especial para que não se cometer aqui 'os mesmos erros dos países desenvolvidos', ou seja, evitar que os custos com saúde se tornem exponenciais, sobretudo pela incorporação de novos materiais e equipamentos sofisticados e de alta tecnologia (ORGANIZAÇÁO PAN-AMERICANA DA SAÚDE; COMISIÓN ECONÓMICA PARA AMÉRICA LATINA Y EL CARIBE, 1997, p. 5-6), supostamente desnecessários.

A contribuição do setor saúde para a dinamização da economia iria desde a produção de bens e serviços complexos ao desenvolvimento científico e tecnológico, com base na demanda de produtos farmacêuticos, equipamentos, vestuários, serviços de informática, hotelaria, alimentação, construção e transporte, o que formaria uma rede intersetorial complexa, incorporando inovações tecnológicas e produzindo efeitos multiplicadores sobre a economia, além de gerar empregos para pessoas de diferentes segmentos da sociedade e de todos os níveis de capacitação profissional, sobretudo mulheres (ORGANIZAÇÃO PAN-AMERICANA DA SAÚDE; COMISIÓN ECONÓMICA PARA AMÉRICA LATINA Y EL CARIBE, 1997). 
Entretanto, a interação 'virtuosa' entre saúde e transformação produtiva não seria fácil de ser alcançada, iria requerer uma açáo política com grande capacidade de coordenaçáo intra e intersetorial. Neste sentido, ao Estado caberia um importante papel: fazer com que os sistemas de saúde incrementassem a eficiência microeconômica e a eficácia na assistência, o que demandaria mudanças institucionais com aceitação de um modelo pluralista de prestação de serviços de saúde - com proeminência do complexo médico industrial -, e envolvendo a colaboração entre os entes governamentais, ONGs, seguros sociais, empresas privadas de prestação de serviços de saúde, organismos internacionais, sindicatos e agremiaçóes (ORGANIZAÇÃO PAN-AMERICANA DA SAÚDE; COMISIÓN ECONÓMICA PARA AMÉRICA LATINA Y EL CARIBE, 1997).

Ao Estado caberia, ainda, promover o uso racional de recursos, pois o livre mercado no setor de saúde nem sempre assegura a eficiência e a eficácia, uma vez que o consumidor não dispóe de todas as informaçóes para decidir, e, quem paga, no caso o Estado, não tem o poder de decisão direta. Daí a preocupação em ampliar a cobertura e moderar o incremento dos custos por meio de um esforço regulatório. Em linhas gerais, o Estado deveria se preocupar com as mudanças no perfil epidemiológico, concentrando suas atividades em açóes programáticas eficazes em função dos custos; definir os problemas prioritários dos diferentes grupos sociais e territoriais; combinar açóes individuais com açóes intersetoriais que melhorassem as condiçóes de vida e de saúde de cada grupo; e garantir uma cesta básica de serviços de saúde. Assim, ele continuaria tendo um papelchave no campo da saúde, sobretudo no que diz respeito ao financiamento do setor; na regulação e controle; e na prestação direta de serviços sanitários. Além disto, seria articulador privilegiado nos acordos de integraçáo regional, visando a criação de normas válidas para todos os países no que se refere a: seguridade social, saúde ocupacional, saúde ambiental, controle de alimentos, medicamentos, tecnologias e prestação transnacional de serviços de saúde, além de regras supranacionais, sobretudo no que diz respeito a alimentos, medicamentos e transferência de tecnologia (ORGANIZAÇÃO PAN-AMERICANA
DA SAÚDE; COMISIÓN ECONÓMICA PARA AMÉRICA LATINA Y EL CARIBE, 1997).

Assumindo como valor e marco de referência a qualidade, a produtividade e a equidade no campo da saúde, o documento apresenta os objetivos e princípios de ação, com destaque para a formulação de políticas que melhorassem a equidade na saúde. Para isso propóe a adoção de medidas que mobilizassem diversos atores e incidissem em distintos âmbitos, tais como:

La coparticipación de los usuarios en el financia-
miento de los servicios, aunada con la focaliza-
ción, contribuiría a ampliar la cobertura de los
segmentos más pobres de la población, a rever-
tir la tendencia del sector al desfinanciamiento
con una canasta básica de servicios de salud y
a establecer un mayor control sobre la evoluci-
ón de los costos y la calidad de las prestaciones.
(ORGANIZAÇÁO PAN-AMERICANA
DA SAÚDE; COMISIÓN ECONÓMICA
PARA AMÉRICA LATINA Y EL CARIBE,
1997, p. 45).

O documento aponta também para a necessidade de mudanças nas políticas de saúde vigentes na grande maioria dos países da região, sendo as principais: sair de um enfoque estritamente setorial para outro que considere as açóes intersetoriais; de um enfoque predominantemente curativo para outro orientado para a prevenção; de um Estado ineficiente, onipresente ou omisso para um Estado regulador e eficiente; de uma gestão centralizada para outra descentralizada e autônoma; de um gasto sem controle e mecânico para outro controlado e que dê prioridade às necessidades dos mais pobres; e de açóes cujos efeitos se desconhecem para programas e projetos adequadamente avaliados segundo metodologias que relacionem os custos com os resultados (ORGANIZAÇÃO PAN-AMERICANA DA SAÚDE; COMISIÓN ECONÓMICA PARA AMÉRICA LATINA Y EL CARIBE, 1997).

Sobre a ação intersetorial, propóe núcleos estratégicos de ação, como educação e saúde; educação, meios de comunicação e promoção da saúde; setor produtivo e meios de comunicação; saúde e ambiente; 
municípios saudáveis; saneamento básico e saúde; e saúde e trabalho.

Assim, as reformas dos setores de saúde, no marco das reformas dos Estados na regiáo, deveriam buscar maior equidade, eficiência e eficácia na formulação de políticas de saúde e na regulamentação, no financiamento, na gestão e na oferta de atenção sanitária. Envolveriam uma reconfiguração das funçóes do Estado a partir do novo perfil assumido com as reformas mais gerais, sendo fundamentalmente: 1) A concertação para definir políticas de desenvolvimento que incrementem a equidade social; 2) A ação multissetorial; 3) A formulação de políticas, o financiamento de programas e a gestão do sistema de saúde; 4) A regulação da produção de bens e serviços de saúde, bem como os agentes que participam da mesma; 5) A promoção e o fortalecimento das relaçóes internacionais de interesse para a saúde; e 6) O acompanhamento e a avaliaçáo do impacto de determinantes, condicionantes e serviços sobre situação de saúde (ORGANIZAÇÃO PAN-AMERICANA DA SAÚDE; COMISIÓN ECONÓMICA PARA AMÉRICA LATINA Y EL CARIBE, 1997).

Sobre a relação público-privado, mesmo admitindo ser essencial a presença do Estado no setor saúde, as reformas defendem que muitas funçóes podem ser desempenhadas pelo setor privado, por meio de regulação mais do que pela execução direta, embora reconheçam áreas conflitivas, como, por exemplo: a disputa por recursos humanos; o objetivo de lucro do setor privado, que não se dispóe a realizar procedimentos menos lucrativos: o pouco controle que o Estado pode ter sobre as atividades do setor privado; e o fato de este setor provocar iniquidades na atenção, uma vez que o mercado da saúde se expande a partir da vontade dos indivíduos e do pagamento direto pela atenção, e não de necessidades epidemiológicas.

Ressalta-se, nesse aspecto, a capacidade e o investimento do complexo médico-hospitalar-farmacêutico na indução ao consumo de seus produtos e serviços pela população, observado nas ultimas décadas.

Ficou explícito que o documento faz coro com outros organismos internacionais, como o Banco Mundial, que defendem o cofinanciamento, a focalização, a descentralização, a terceirização e a oferta de uma cesta básica de serviços de saúde em detrimento da integralidade e de sistemas universais. Esta cesta teria a amplitude da disponibilidade de recursos de cada país e das preferências sociais e opçóes políticas adotadas. Com a cesta, se fixaria a linha de corte da atenção à saúde que o Estado se comprometeria a ofertar gratuitamente para todos.

A defesa da focalização, entendida como a ação de concentrar recursos financeiros disponíveis em uma população definida e em grupos vulneráveis e pobres, se baseia no entendimento de que a população é heterogênea, tornando necessárias açóes dirigidas aos grupos excluídos com características similares, aumentando, assim, a eficácia e a eficiência das intervenções (ORGANIZAÇÃO PAN-AMERICANA DA SAÚDE; COMISIÓN ECONÓMICA PARA AMÉRICA LATINA Y EL CARIBE, 1997).

O impacto redistributivo que a focalização poderia promover dependeria da clara identificação dos grupos vulneráveis. Para isto, são propostos dois critérios: o primeiro deveria privilegiar os grupos especiais de risco afetados de forma mais intensa do que a média da população, ou que enfrentam barreiras para ter acesso aos serviços de saúde, como, por exemplo, mulheres, crianças, idosos e as minorias étnicas; o segundo seria o critério epidemiológico, dirigido aos problemas de saúde de alta prevalência, com o uso de tecnologias com custoefetividade comprovado. Contudo, a OPAS/CEPAL (1997) ressalta que, ao focalizar, podem-se cometer erros, como a filtragem de benefícios para setores alheios à população-objeto, ou levar a falhas de cobertura.

Sobre o financiamento do setor, o documento reconhece a necessidade de os países da região aumentarem os recursos destinados aos setores sociais, em geral, e à saúde, em particular, defendendo a ideia de que o Estado deve liderar, com uma 'conduta ativa', o processo de redefiniçãa e adequação das fontes de financiamento e mecanismos de transferências que possam contribuir para elevar o nível de saúde de toda a população. A OPAS/CEPAL concorda que na maioria dos países da regiấo a distribuição dos gastos sociais é regressiva, sendo que o aumento dos gastos públicos não tem se traduzido em elevação dos níveis de bem-estar dos pobres, o que indicaria a necessidade de melhorar 
a eficiência na aplicação dos recursos, visando a uma maior equidade e aos impactos positivos que uma população saudável provocaria na economia nacional.

Contudo, ressaltam que o aumento dos investimentos em saúde não deve implicar em aumento da carga tributária, embora reconheçam que esta, na região, é inferior à dos países desenvolvidos e que há muitas diferenças intrarregionais indicando que, em alguns casos, poderia haver maior tributação para obter os recursos necessários aos setores sociais, inclusive com impostos específicos para a saúde, o que impediria a redução de recursos em momentos de crises. Recomendam ainda que os países considerem a possibilidade de reduzir os gastos militares e de empresas estatais ineficientes, redirecionando-os para gastos sociais. Por fim, lembram que outras fontes de recursos para o setor saúde poderiam ser: a contribuição dos trabalhadores, recursos externos e recursos privados (ORGANIZAÇÃO PAN-AMERICANA DA SAÚDE; COMISIÓN ECONÓMICA PARA AMÉRICA LATINA Y EL CARIBE, 1997).

O documento se conclui com a indicação dos resultados esperados, sendo o principal a universalização do acesso a serviços de saúde em um período relativamente curto, garantindo à população um mínimo de atençáo com o menor custo possível. Para isto, seria imprescindível ampliar a infraestrutura sanitária básica, ampliar a capacidade instalada e melhorar a eficiência setorial e intersetorial no campo da saúde. Mas, reconhecem que a implementação da proposta de Saúde Transformação Produtiva com Equidade (STPE) e a transformação da saúde em uma política de Estado dependeria de vontade política, de conhecimento técnico e do envolvimento de múltiplos atores e setores sociais.

\section{Considerações Finais}

Passadas duas décadas do momento em que foram divulgadas essas propostas, é possível afirmar que as proposiçóes cepalinas, que pretendiam fundar um novo padrão de desenvolvimento para a América Latina, se constituíram em matriz orientadora de muitos governos da regiáo, tanto no campo da economia como no das políticas sociais.

Acredita-se que a assimilação e a vigência de elementos dessas propostas decorrem, entre outras razóes, da associação de categorias econômicas com categorias advindas do campo da filosofia política e moral, fundamentalmente, a noção de equidade associada à de justiça - compreendida como uma forma de ordenamento equitativo do sistema social -, que torna mais palatável o projeto liberal, sem necessidade de transformaçóes estruturais, uma vez que não importam os resultados, desde que sejam considerados justos pela sociedade específica.

No caso dos documentos analisados, isso se evidencia na ênfase da equidade e na manutenção da neutralidade analítica, transferindo para cada sociedade a responsabilidade de definir o nível de equidade almejado e o mínimo de saúde pretendido, a partir de suas condiçóes e dos consensos internamente possíveis a cada sociedade. Assim, não se toca na dinâmica de acumulação capitalista, na divisão internacional do trabalho, nas relaçóes que se estabelecem intra e entre países no que diz respeito à exploração e à acumulação, e, muito menos, nos antagonismos existentes nessas sociedades.

A diferença que parece existir na proposta de saúde da OPAS/CEPAL em relação à de outros organismos internacionais é dada pela tentativa de articular certa noção de desenvolvimento com saúde a partir do conceito de enfoque integrado. No entanto, no que se refere às propostas de açôes e políticas para o campo da saúde, não se diferencia substancialmente das proposiçóes de outros organismos, que desde fins da década de 1980, não só apresentaram propostas de reformas para o setor saúde dos países periféricos, fundamentadas no princípio da seletividade e da focalização nos pobres, como financiaram projetos visando à implementação dessas reformas.

As consequências para o campo da saúde da adoção dessas proposiçóes podem ser, a exemplo do que tem ocorrido no Brasil, (1) o abandono da luta por direitos já consagrados constitucionalmente, como o direito à saúde integral e igualitária para todos, em face da impossibilidade de o Estado atender a todas as demandas neste campo; (2) a adoção da equidade 
como critério para resolver o problema da falta de recursos financeiros, de pessoal e da própria oferta de serviços de saúde; (3) a ampliação do setor privado na oferta de serviços de saúde por meio de planos e seguros de saúde; e (4) a concentração da oferta de Serviço Auxiliar de Diagnóstico e Terapia (SADT) no setor privado, tendo como grande comprador o setor público.

\section{Referências}

BREILH, J. Las tres 'S' de la determinación de la vida: 10 tesis hacia una visión crítica de la determinación social de la vida y la salud. In: NOGUEIRA, R. P. (org.). Determinação social da saúde e reforma sanitária. Rio de Janeiro: CEBES, 2010. p. 87-125.

COMISIÓN ECONÓMICA PARA AMÉRICA LATINA Y EL CARIBE. Informação histórica. Santiago, Chile: CEPAL, 2006. Disponível em: <http://wwww.eclac.org>. Acesso em: 10 abr. 2006.

Equidad y transformación productiva: un enfoque integrado. Santiago, Chile: CEPAL, 1992. Disponível em: <http:// www.eclac.org/publicaciones/xml/3/4373/lcg1701e.htm>. Acesso em: 02 out. 2008.

Transformación productiva con equidad: la tarea prioritaria del desarrollo de América Latina y el Caribe en los años noventa. Santiago, Chile: Nações Unidas/CEPAL, 1990.
ORGANIZAÇÃO PAN-AMERICANA DA SAÚDE; COMISIÓN ECONÓMICA PARA AMÉRICA LATINA Y EL CARIBE. Salud, equidad y transformación productiva en América Latina y el Caribe. Santiago, Chile: Washington, DC. 1997. (Cuaderno técnico, n. 46).

RAWLS, J. Uma teoria da justiça. São Paulo: Martins Fontes, 1997. Justiça como equidade: uma reformulação. São Paulo: Martins Fontes, 2003.

SCHULTZ, T. W. O Capital humano: investimento em educação e pesquisa. Rio de Janeiro: Zahar Editores, 1973.

SCHINCARIOL, I. IBGE: quase 9\% do PIB foi gasto com bens e saúde. Disponível em: <http://www.ensp.fiocruz.br/portal-ensp/ informe/site/materia/detalhe/29136>. Acesso em: 02 jul. 2012.

Recebido para publicação em Abril/2012.

Versão final em Dezembro/2012

Conflito de interesse: Não houve.

Suporte financeiro: Pesquisa financiada com Recursos da Fundação Araucária. 